\title{
Biotreatment of Produced Waters for Volume Reduction and Contaminant Removal
}

by

M. Cristina Negri and Ray R. Hinchman

Argonne National Laboratory, 9700 S. Cass Avenue, Argonne IL 60439

Jerry Mollock

Devon Energy Corporation, 20 N. Broadway, Suite 1500, Oklahoma City, OK 73102

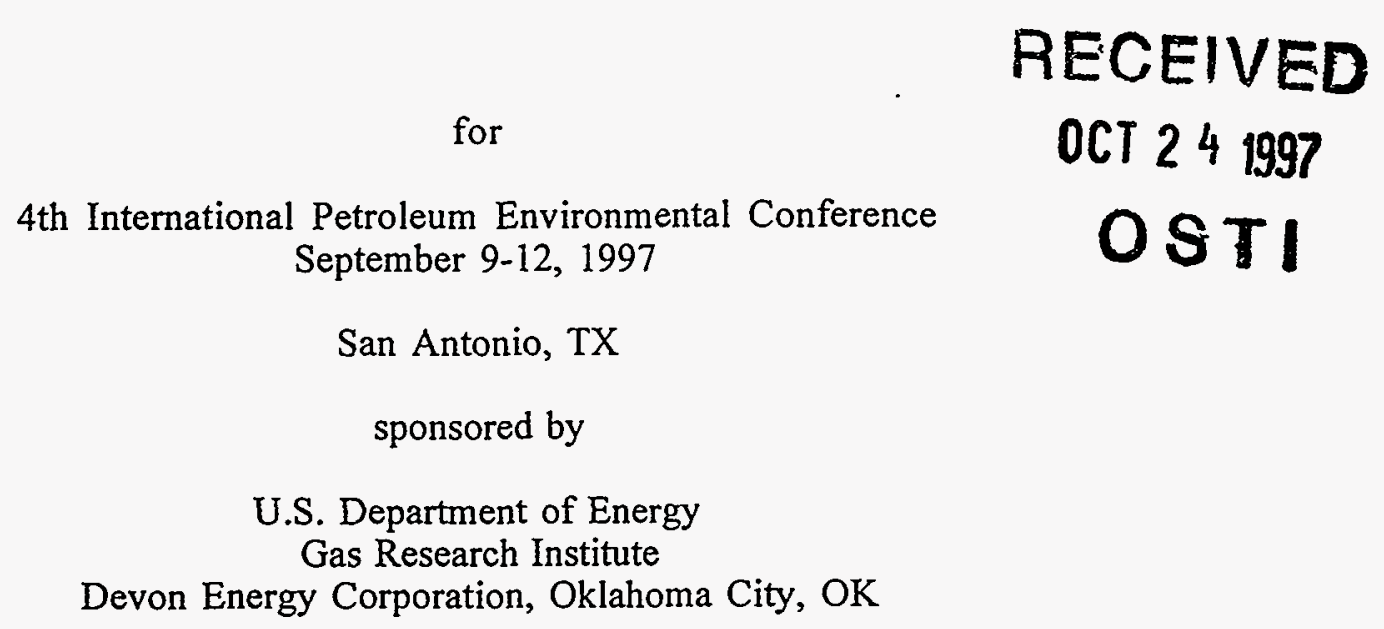

The submitted manuscript has been created by the University of Chicago as Operator of Argonne National Laboratory ("Argonne") under Contract No. W-31-109-ENG-38 with

the U.S. Department of Energy. The U.S. Government retains for itself, and others acting on its behalf, a paid-up, nonexclusive, irrevocable worldwide license in said article to reproduce, prepare derivative works, distribute copies to the public, and perform publicly and display publicly, by or on behalf of the Government. 


\section{DISCLAIMER}

This report was prepared as an account of work sponsored by an agency of the United States Government. Neither the United States Government nor any agency thereof, nor any of their employees, makes any warranty, express or implied, or assumes any legal liability or responsibility for the accuracy, completeness, or usefulness of any information, apparatus, product, or process disclosed, or represents that its use would not infringe privately owned rights. Reference herein to any specific commercial product, process, or service by trade name, trademark, manufacturer, or otherwise does not necessarily constitute or imply its endorsement, recommendation, or favoring by the United States Government or any agency thereof. The views and opinions of authors expressed herein do not necessarily state or reflect those of the United States Government or any agency thereof. 


\section{DISCLAMIER}

Portions of this document may be illegibie in electronic irogge produets. Images are produced from the best available original docoment. 


\title{
Biotreatment of Produced Waters for Volume
}

\section{Reduction and Contaminant Removal}

\author{
M. Cristina Negri and Ray R. Hinchman \\ Argonne National Laboratory, 9700 S. Cass Avenue, Argonne IL 60439 \\ Jerry Mollock \\ Devon Energy Corporation, 20 N. Broadway, Suite 1500, Oklahoma City, OK 73102
}

\begin{abstract}
Produced water is wastewater that is brought to the surface from natural gas wells during natural gas production. Its constituents, mostly salt, with traces of hydrocarbons and heavy metals, are a significant disposal problem. Argonne National Laboratory (ANL), in partnership with the Gas Research Institute (GRI), has developed a low-cost, low-tech method, in which green plants are used to reduce the volume of produced water. We have designed an engineered bioreactor system, which is modeled after natural saline wetland ecosystems. The plant bioreactor system maximizes plant evapotranspiration to reduce wastewater volume and, concurrently, may function as a "biological filter" to enhance contaminant degradation and immobilization in the root/rhizosphere zone. Halophyte plant species having high salt tolerance and high transpiration rates were selected after we tested them in greenhouse experiments. Models obtained by using our greenhouse findings reduced the volume of the wastewater (up to $6 \%$ salt) by $75 \%$ in about 8 days. A field demonstration of the bioreactor, designed on the basis of the results from the greenhouse study, is successfully under way at a natural gas well site in Oklahoma. The process could offer the petroleum industry a low-cost biological alternative to existing expensive options.
\end{abstract}




\section{TECHNICAL CONCEPT AND OBJECTIVES}

Water that is brought to the surface from gas wells during natural gas production is called "produced water." This water originates from the same geologic formation as the gas; ancient marine deposits, many of which also produce oil, as well as coal beds of various geologic age, characterize the geologic fermentation. The constituents of produced water reflect their origin. Perhaps the most common characteristic of produced waster is elevated concentrations of dissolved salt, often greater than those in sea water. Other constituents can include bicarbonates, carbonates, sulfates, hydrocarbons and other organics, trace elements, and heavy metals. The disposal of produced water is subject to EPA regulations (1), and the costs of current treatment and disposal methods are becoming unacceptably high.

Water constitutes $70-90 \%$ of a plant's total weight and is essential for plant nutrition and growth. For the majority of plants, the uninterrupted absorption of water by the roots, its translocation to other plant tissues, and its evaporation through leaf stomata (transpiration) is fundamental for survival. Water makes possible the production of biomass by photosynthesis and the absorption of inorganic nutrients (such as nitrogen, phosphorus, etc.). Evapotranspiration is the loss of water by direct evaporation from a water surface, plus that by plant transpiration. Plants, and especially crops, differ by the amount of biomass they can generate per unit of water utilized. This ratio describes a plant's water-use efficiency. In the usual concept, a plant is efficient when it can produce a high amount of biomass while using very little water. We reversed this concept in the development of a waste-treatment method that used green plants to reduce the volume of produced waters.

The use of natural, engineered, or constructed wetlands to decontaminate wastewaters has been demonstrated in numerous operating systems throughout the United States. These existing systems are most often used to treat acid mine drainage or municipal sewage (2). The efficacy of wetland ecosystems as wastewater treatment systems is based on the well-known ability of wetland plants and their associated rhizospheres to concentrate and degrade highly dilute contaminants.

To develop biological treatment systems for saline produced waters, a logical approach is to look to the plants that have already developed a natural ability to grow and be highly productive at high external salinity levels. Those plants that occupy the highly saline habitats along sea coasts; in salt and brackish marshes; in estuaries; and in dry, saline interior habitats have already undergone strong selection for their ability to tolerate salt. This large pool of plants provides numerous candidates for use in engineered, plant-based systems designed to treat saline wastewater.

For this paper, halophytes are defined as plants found growing under naturally saline conditions - a broad, but acceptable, definition (3). Basically, higher plants have two mechanisms for tolerating high external salt concentrations, and these are fundamentally different. Some halophytes accumulate salt to high levels in their tissues, whereas others typically exclude the salt (4). An ability to exclude salts does not come without a price. The compensatory processes that must occur in the tissues to maintain osmotic balance in the absence of high internal salt 
concentrations consume energy and substrates that might otherwise have gone into growth. Thus, it is not surprising to observe a decrease in growth and plant stature in these species as the salt concentration in the growth medium increases. Furthermore, there is a limit of salt concentration beyond which even halophytes cannot grow or live.

The goal of the Biotreatment of Produced Waters Project at ANL was to develop, investigate, and evaluate the principal components of a cost-effective engineered ecosystem, called a contained plant-bioreactor system, that will, through natural plant processes, reduce the volume and contaminant concentrations in saline wastewater produced in the course of natural gas extraction. The bioreactor system uses natural saltmarsh ecosystems as a model and incorporates salt-tolerant wetland plant species and new, innovative hydroponic plant growth techniques.

Specific objectives of our work included the following:

- Develop a database of candidate halophyte species from wetland, upland, and arid natural habitats and a wide array of plant families having attributes appropriate for use in a plant bioreactor to treat saline-produced waters.

- Conduct greenhouse experiments to determine, in the most promising candidate plant species, the salt tolerance and evapotranspiration rates.

- Utilize data and information from the greenhouse experiments to develop a model of the bioreactor and test it at a pilot scale to obtain data on its performance and economic feasibility.

\section{MATERIALS AND METHODS}

\section{Greenhouse Experimental Procedures}

An early effort in this project was the development of a detailed database of candidate halophyte species (from wetland, upland, and arid natural habitats and a wide array of plant families) having attributes appropriate for use in plant bioreactor systems to treat saline produced waters. A profile for an "ideal" bioreactor plant was developed, which included considerations of a plant's salt tolerance, transpiration rate, biomass production, nutrient requirements, ease of propagation, and end-use options.

Candidate plant species (see Table 1) were then tested at three initial salt concentrations $(0 \%, 1.5 \%$, and $3 \%)$ in nutrient solution. Each treatment was replicated three or four times. Each replicate consisted of several plants growing in a plastic bucket with the appropriate nutrient solution bathing the roots. The first four species tested (Spartina alterniflora, Sporobolus virginicus, Salicornia virginica, and Cladium jamaicense) were grown in buckets with a capacity of $2.5 \mathrm{~L}$. The two most 
recent species tested (Spartina alterniflora var Vermilion and Scirpus validus) were grown in 19-L buckets because of their considerably larger size.

The nutrient solution used for the salt-tolerance/evapotranspiration experiments was a slightly modified standard Hoagland's solution (5). Greenhouse supplemental lighting was provided by two banks of Sylvania Maxi-Grow 1,000-w fixtures with broad-spectrum Metalarc lamps. Experiments conducted between November and April were set up under these lights.

After one to several weeks of acclimatization and growth in the nursery trays, a set of transplants (obtained from commercial or research sources) was placed in the experimental buckets to determine salt tolerance and evapotranspiration rates. The plants in each bucket were supported by a styrofoam float. Each plant was placed in a hole in the float that was just large enough to support the plant at the transition between stems and roots. The float fit snugly inside the bucket and maintained root immersion in the nutrient solution regardless of the depth. The styrofoam floats also inhibited direct evaporation of water from the surface of the nutrient solution in the buckets with plants. Thus, most water loss from the buckets with plants was assumed to be via transpiration. Another set of replicate buckets containing nutrient solution (but without floats or plants) was used to measure direct evaporation from the open liquid surface.

Total water loss from both the open water buckets and the plant buckets was measured directly by using a simple mass-balance technique. The mass balance technique integrated, over at least $24-\mathrm{h}$ period, the highly fluctuating rates of evapotranspiration and evaporation, as well as the major factors that affect these rates (insolation, sensible heat, temperature, humidity, and air movement), which also fluctuate on short time scales. The water depth in millimeters was measured in each experimental and nutrient-only bucket by using a float gauge developed specifically for this purpose. This value was subtracted from the previous depth measurement for that bucket to obtain the net difference; the net difference was then converted to a volume measurement that represented the amount of water evapotranspired or evaporated during the time interval between measurements. This value was further manipulated mathematically to standardize all readings to $24-\mathrm{h}$ intervals.

The salt concentration in the nutrient solution of the experimental buckets (both with and without plants) was determined by measuring the electrical conductivity of the solution with a sensitive conductivity meter at $24-$ or $48-\mathrm{h}$ intervals. The meter was calibrated against a set of $\mathrm{NaCl}$ solutions in nutrient of known concentration, as well as a certified conductivity standard.

In each bucket, evapotranspiration was allowed to continue until the solution level was either $1 \mathrm{~cm}$ or less in the small buckets or $5 \mathrm{~cm}$ or less in the large buckets. After the current depth and conductivity measurements were recorded, a known volume of nutrient at the same salt concentration as the starting concentration was added to the bucket to bring the volume close to the original volume. The new salt concentration was then higher than the original (all of the salt added to the bucket remained, only water was lost), but not as high as the concentration just before the addition. Thus, the experimental plants experienced a fluctuating, but generally increasing, salt concentration over the course of the experiment. To an extent, this regime paralleled the normal salt fluctuations to which saltmarsh plants are exposed 
as a result of tidal changes, drying, and the dilution of sea water in saturated wetland soil by rainfall.

By using this procedure, it was possible to measure evapotranspiration over an essentially continuous range of salt concentrations, up to the salt tolerance limit of the species. As this limit was approached, the plants usually underwent changes characterized by a slowing or cessation of growth, severe wilting, drying up of the leaves, and eventually death.

\section{Development of a Bioreactor Model and Field Verification at Pilot Scale}

The results from the greenhouse studies were used to develop a concept of the bioreactor and to generate a model of it that would predict its effectiveness at reducing the volume of produced water. Such a bioreactor was conceived as being composed of two connected wastewater-processing compartments, each containing different, and possibly multiple, plant species. The wastewater is pumped into the first compartment and remains there until the water attains (via evaporation and plant transpiration) a higher salinity level and a concomitant reduction in volume. The salinity level of each compartment is determined by the tolerance of the plants in that compartment. The water must be removed and replaced by lower salinity wastewater before it begins to have adverse, high-stress effects on the plants in that compartment. To do this, the wastewater (reduced in volume and higher in salinity) is gravity moved (like in two adjacent rice paddies) to the next compartment, which contains plants of higher salt tolerance than the previous upstream compartment, and the process is repeated.

Among the candidate plant species studied in the greenhouse tests, Scirpus validus was chosen to grow in the first compartment, because of its higher evapotranspiration rates and lower salt tolerance. Spartina alterniflora was chosen to grow in the second compartment, which received wastewater at a higher salinity level.

On the basis of conservative evapotranspiration values (about $40 \%$ of the max greenhouse rates), a bioreactor model was designed to treat $66.6 \mathrm{~m}^{3}$ of produced water using a total surface of $300 \mathrm{~m}^{2}$ (Fig. 4).

An experimental pilot-scale batch processing bioreactor has been assembled on the basis of our model and is operating (third year) at Devon Energy Corp. The unit is successfully operating on $100 \%$ produced water and being monitored for volume reduction, salinity, and contaminants. The batch processor is made of two separate troughs, each with a capacity of approximately $0.7 \mathrm{~m}^{3}$, which are processing wastewater of increasing salinity. The plant species used include Scirpus validus, Spartina alterniflora, and $S$. Alterniflora Var. vermilion (Fig. 5). 


\section{Results and Discussion}

The data from the greenhouse experiments to date are presented in Figs. 1-3.

Figure I shows, for each species tested to date, the mean total plant biomass per container (averaged over the entire experimental run) plotted against the evapotranspiration rate at $2 \%$ salinity on a per-container basis.

Although the maximum rates were attained for a relatively small part of the total experimental run, they represent the potential of a particular species under near-optimum conditions within the limits of the greenhouse conditions used. The maximum rates were attained over a minimum of a $24-\mathrm{h}$ period and are not instantaneous rates. The conditions favoring high plant-evapotranspiration rates include high insolation and sensible heat, adequate water availability to the root system, low humidity, and adequate air movement through the plant canopy to sweep away the transpired water vapor.

The mean values for evapotranspiration represent the mean of all the measurements at a particular salt concentration. The mean includes many measurements made on cloudy, cool, or humid days when there was little or no net water loss by the plant containers. A summary of evapotranspiration rates for all plant species tested is given in Fig. 2.

Spartina alterniflora (saltwater cordgrass) had a high total evapotranspiration rate ( $\mathrm{mL} /$ container-day) because of its high initial biomass, growth form, and good growth during the experiment. Cordgrass grows to a large size (up to $1.5 \mathrm{~m}$ ) in its natural habitat. Its growth habit of multiple, long, flat leaves provides a large surface area of transpiring tissue. This plant would be an excellent component in a plant bioreactor system because it maintained a mean per-container evapotranspiration rate that was higher than the open water evaporation rate when grown in a salt concentration of almost $6 \%$ (Fig. 3). The per-gram, fresh-weight evapotranspiration rate paralleled the total rate. Saltwater cordgrass would be appropriate for the downstream (higher salinity) compartments of the proposed bioreactor system. However, a similar salt-tolerance/evapotranspiration experiment on this species should be conducted during the winter months with supplemental lighting to determine if it becomes dormant in winter, as has been observed in many other saltmarsh species. Winter dormancy could slow both growth and evapotranspiration rates, as described in the discussion below for Spartina alterniflora var Vermilion.

Sporobolus virginicus - coastal dropseed - has the highest evapotranspiration rate for the per-gram, fresh-weight basis of any halophyte tested to date. Dropseed is also very salt-tolerant, but its natural growth habit is small compared with that of cordgrass. Total biomass per container was therefore lower, which resulted in lower evapotranspiration rates per container.

Salicornia virginica - perennial glasswort - is a true halophyte that is very salt-tolerant and takes up salt to relatively high concentrations in its tissues. Its growth rate is relatively slow, and its natural growth habit is small compared with that of the grasses tested. Because of these factors, its evapotranspiration rates on a percontainer basis were the lowest of the species tested to date. However, it maintained 
a per-container evapotranspiration rate that was higher than the open water rate when grown in a salt concentration of over $2 \%$ in the nutrient solution.

Cladium jamaicense - sawgrass - is a sedge of medium stature that attains a height of $1-3 \mathrm{~m}$ in its natural habitat. In these experiments, it showed good salt tolerance and acceptable rates of evapotranspiration on a per-container basis. Growing in nutrient solutions up to $3 \%$ salt, the maximum per-container evapotranspiration rates were relatively high, and the mean rate was considerably above the open water rate. These results indicate that under bioreactor conditions, there is good potential to increase the evapotranspiration rates well above the mean rates attained here by optimizing growing and climatic conditions. Cladium has low nutrient requirements and would be a good candidate species for the moderate salinity compartments of a bioreactor system.

Vermilion cordgrass is a variety of Spartina alterniflora from Florida. Its natural growth habit is considerably larger and more robust than the standard cordgrass discussed above. However, its evapotranspiration rates, both on a percontainer and a per-gram fresh-weight basis, were considerably lower than those of the smaller cordgrass, probably because it is dormant during part of the winter. Even though the mean per-container evapotranspiration rates was relatively low, they were consistently above the open water evaporation rates when the plant was grown a nutrient solution containing over $5 \%$ salt.

Great bulrush exhibited very high evapotranspiration rates and growth (biomass production) when maintained in salinities of up to $3 \%$. The available data indicate that these rates may drop considerably at higher salt concentrations. The evapotranspiration rates on a per-container basis were the highest for any plant tested to date. Bulrush also had the largest difference (higher) between the mean per-container evapotranspiration rates and the open water rates when grown in nutrient solution containing up to $3 \%$ salt. The high rates are maintained at the per-gram, fresh-weight level. These early results indicate that bulrush would be an ideal candidate for the lower salinity compartments of the proposed bioreactor system.

Salicornia and Cladium both had higher evapotranspiration rates under saline conditions than in nutrient solution without salt. This response is common in highly salt-tolerant plants and is an example of the tendency of plants to grow and function best under the conditions to which they are adapted, even when these conditions are more harsh than conditions to which these plants may be occasionaily exposed (e.g., salt dilution by tidal flushing or rainfall in the halophyte's habitat) (6).

Observations during several experimental runs indicate that, under a variety of conditions, mature grass plants are more effective at maintaining high evapotranspiration rates than an equal biomass of young plants. Grass plants have high evapotranspiration rates probably because, they gradually lose control of water balance as their leaves mature. As the epidermis and cuticle thicken, stomatal function is reduced. Essentially, older leaves transpire at near maximum rates as long as an adequate water supply is available.

In these greenhouse experiments, the maximum evapotranspiration rates occurred during the summer months on clear, warm, sunny days with low humidity. In the greenhouse, the movement of air by the exhaust fans, and the relatively small 
amount of plant aerial biomass in relation to the total volume of the greenhouse, permitted high evapotranspiration rates. Data from the greenhouse were used to provide an estimate (model) of the time required per surface area to reduce produced water volume of $75 \%$. Using a conservative value of $40 \%$ of the maximum ET rates for the plants selected for growth in the bioreactors, we estimated that a total surface of $300 \mathrm{~m}^{2}$ (200 for the first stage, and 100 for the second) at a depth of $30 \mathrm{~cm}$ $\left(67 \mathrm{~m}^{3}\right.$ of incoming wastewater) would be reduced $75 \%$ in volume in 7.6 days.

\section{Conclusions}

Argonne's greenhouse studies to date have verified the hypothesis that the primary factors determining the amount of water lost from a closed system (e.g., a plant bioreactor) via plant evapotranspiration is the total aerial biomass of transpiring tissue and its surface area. Larger values for each of these factors (biomass and surface area) result in higher evapotranspiration rates and water loss, as well as more rapid reduction of the water volume from the closed system. This relationship was observed for all species tested and at all salinities of the hydroponic nutrient medium (up to $6 \%$ salt).

Large, robust species of grasses or grasslike plants (sedges and rushes) best match the profile of the "ideal plant" that was developed, and those exhibiting moderate to high salt tolerance (halophytes native to salt or brackish marshes or coastal environments) would be appropriate for bioprocessing saline produced water. Bioprocessing in this context includes volume reduction through evapotranspiration and contaminant reduction via the biological filtering effect of the root system and its associated rhizosphere.

Of the species tested to date, those best matching the "ideal plant" profile were Spartina alterniflora (saltwater cordgrass), Cladium jamaicense (sawgrass), and Scirpus validus (great bulrush).

For all species tested, the mean per-container evapotranspiration rates were consistently above the open water evaporation rates when maintained in nutrient solution with a concentration of $2 \%$ salt. For several species, the higher rate was maintained when grown in nutrient solution with salinities of up to $6 \%$.

For all species tested, evapotranspiration rates expressed as milliliters per gram fresh-weight per day were a poor predictor of "total" evapotranspiration rates (mL/container/day), which depended on the total amount of plant biomass in each container. The total biomass per container depended, in turn, on the natural size and growth characteristics of the species. Thus, the general rule of thumb is, within a group of salt-tolerant plants, the bigger and more robust the plant, the higher the total evapotranspiration rate.

Winter dormancy in candidate bioreactor plants is a potential problem that requires additional research. Winter dormancy could slow both growth and evapotranspiration rates of certain plants in greenhouse-based bioreactors, particularly in the higher latitudes of the United States. In these areas, during winter, insolation, sensible heat, and humidity inside the greenhouse are lower and the days 
are shorter. All of these factors affect plants in their natural environment. The relationship between winter dormancy in candidate bioreactor plants and the intensity and quality of supplemental greenhouse lighting also needs further study.

The model data are currently being verified at a field site by Devon Energy Corporation in Oklahoma. Their field demonstration confirmed the data predicted by the model, which achieved a $75 \%$ volume reduction of produced waters in less than eight days by using a total surface of $300 \mathrm{~m}^{2}$.

\section{Acknowledgements}

This work was carried out by Argonne National Laboratory and sponsored by the Gas Research Institute and Devon Energy Corporation, Oklahoma City, OK.

\section{References}

1. U.S. EPA, "Wastes from the Exploration, Development, and Production of Crude Oil, Natural Gas, and Geothermal Energy," Technical Report EPA/530-SW-86-051, Office of Solid Waste and Emergency Response (1986).

2. Heliotis, F.D., "Wetland Systems for Wastewater Treatment: Operating Mechanisms and Implications for Design," IES Report 117, Instructional Program, Institute for Environmental Studies, University of Wisconsin-Madison (1982).

3. Aronson, J.A., "HALOPH - A Data Base of Salt Tolerant Plants of the World. Office of Arid Lands Studies," The University of Arizona, Tucson, Arizona (1989).

4. Sutcliffe, J.F., Mineral Salts Absorption in Plants, Pergamon Press, New York (1962).

5. Hoagland, D.R., and Arnon, D.I., "The Water Culture Method for Growing Plants Without Soil," Circular 347, California Agricultural Experiment Station, Berkeley (1950).

6. Long, S.P. and Mason, C.F., Saltmarsh Ecology, Blackie - Chapman and Hall, New York (1983). 
Table 1. Plants Tested to Date.

\begin{tabular}{llll}
\hline Scientific Name & Common Name & Plant Family & Code \\
\hline Spartina alterniflora & saltwater cordgrass & Poaceae & Spal \\
Sporobolus virginicus & dropseed & Poaceae & Spvi \\
Salicornia virginica & perennial glasswort & Chenopodiaceae & Savi \\
Cladium jamaicense & sawgrass & Cyperaceae & Clja \\
Spartina alterniflora & saltwater cordgrass & Poaceae & Spal-V \\
var Vermilion & & & \\
Scirpus validus & great bulrush & Cyperaceae & Scva \\
\hline
\end{tabular}


Figure 1. Biomass per Container and Evapotranspiration (ET) at $2 \%$ Salt.

Figure 2. Halophyte Evapotranspiration (ET) and Open Water Evaporation.

Figure 3. Evapotranspiration by Spartina Alterniflora vs. Open Water Evaporation.

Figure 4. Plant Bioreactor Model.

Figure 5. The Pilot Demonstration of the Halophyte Bioreactor at Devon Energy Company. 
Figure 1

Biomass per Container and Evapotranspiration (ET) at $2 \%$ Salt

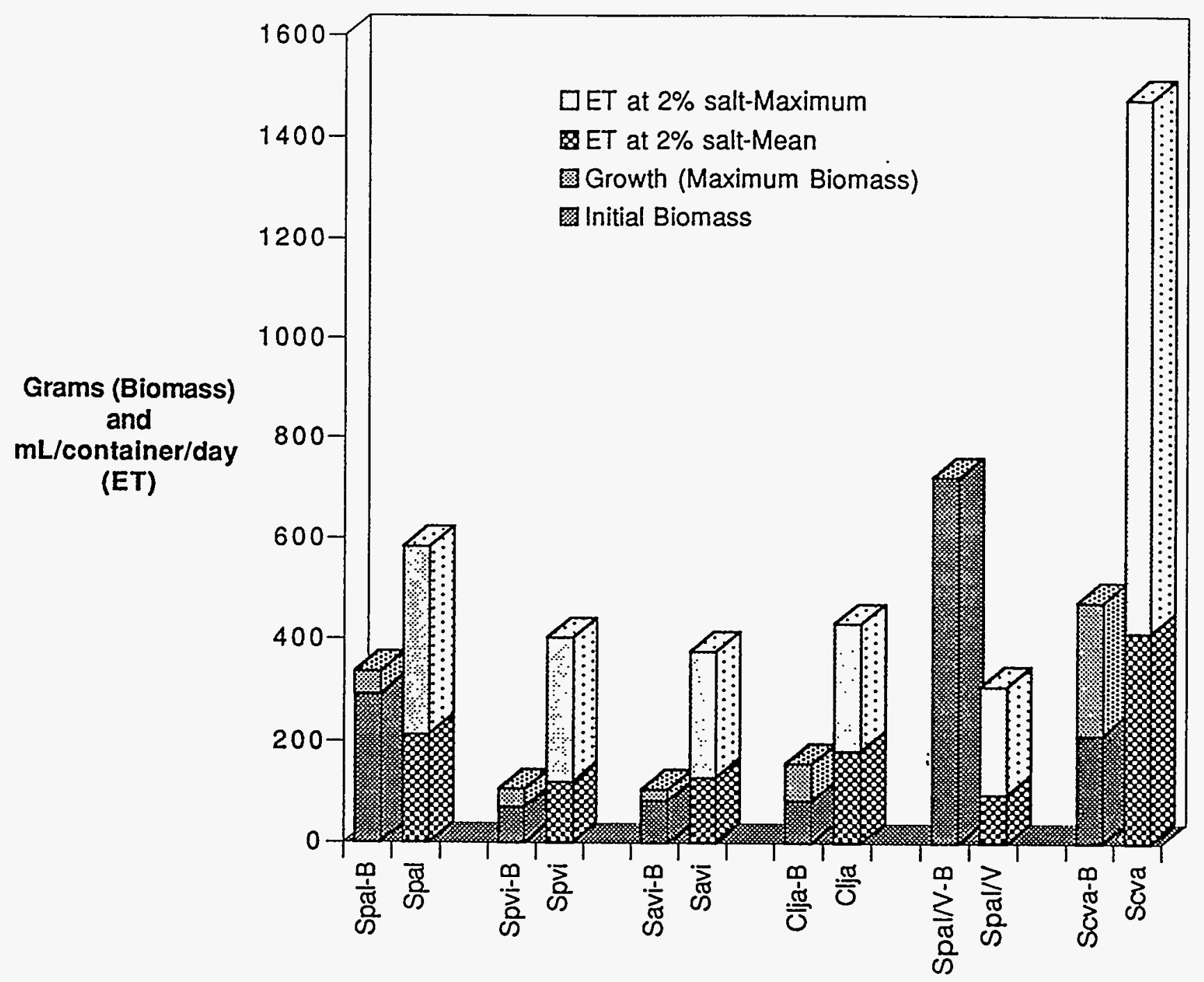


Fig. 2.

Halophyte Evapotranspiration (ET) and Open Water Evaporation

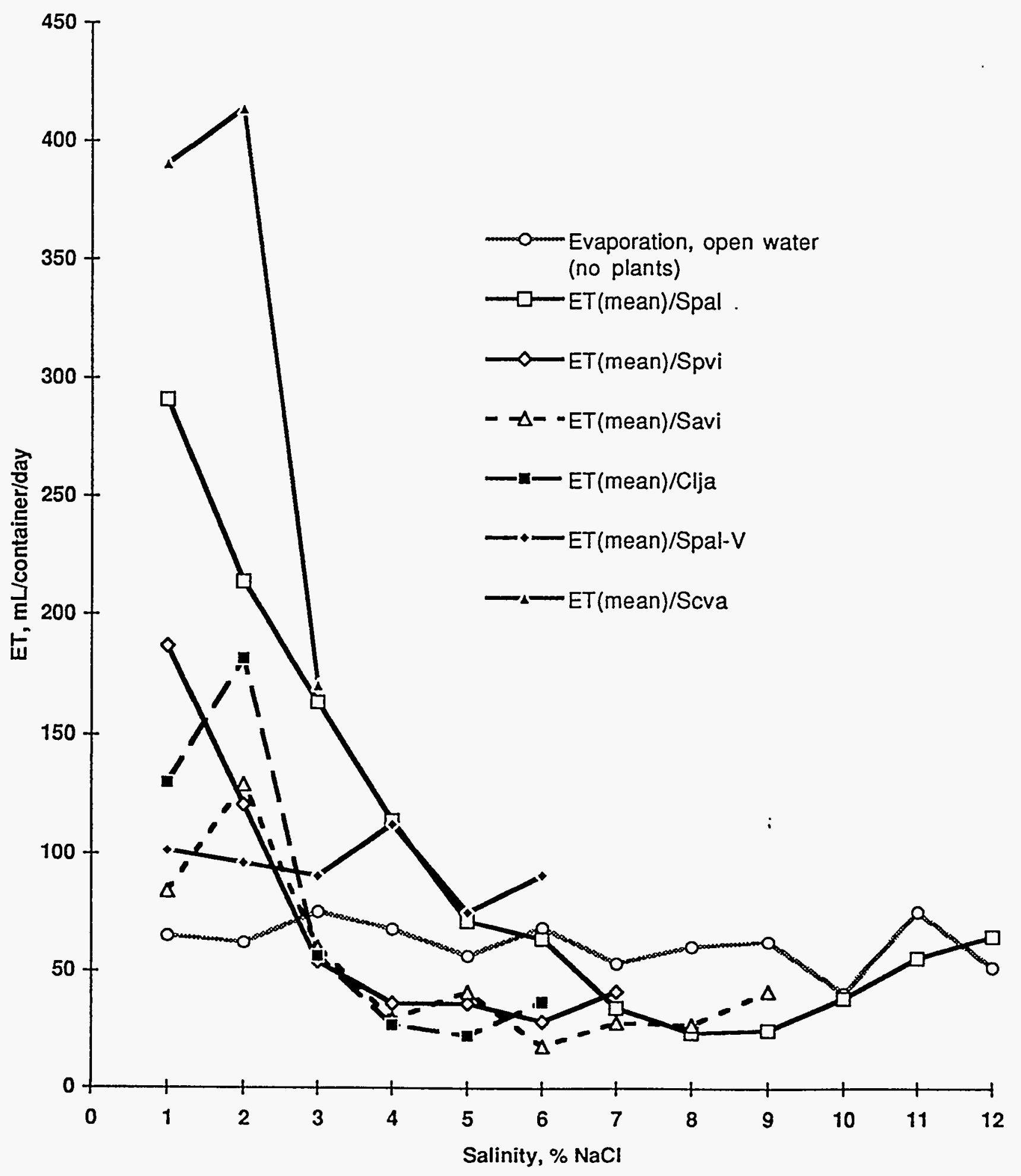




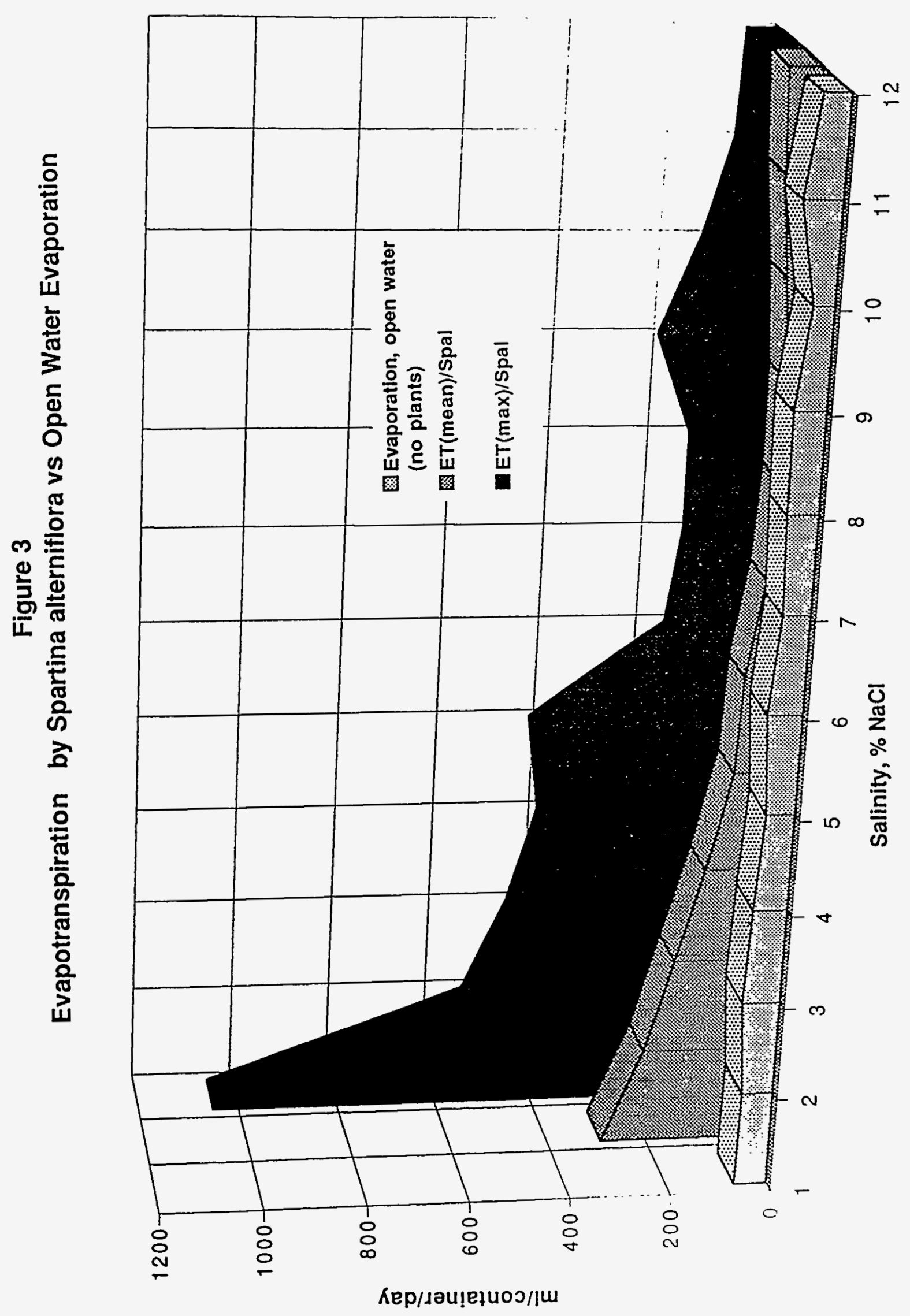


Figure 4

\section{PLANT BIOREACTOR MODEL}

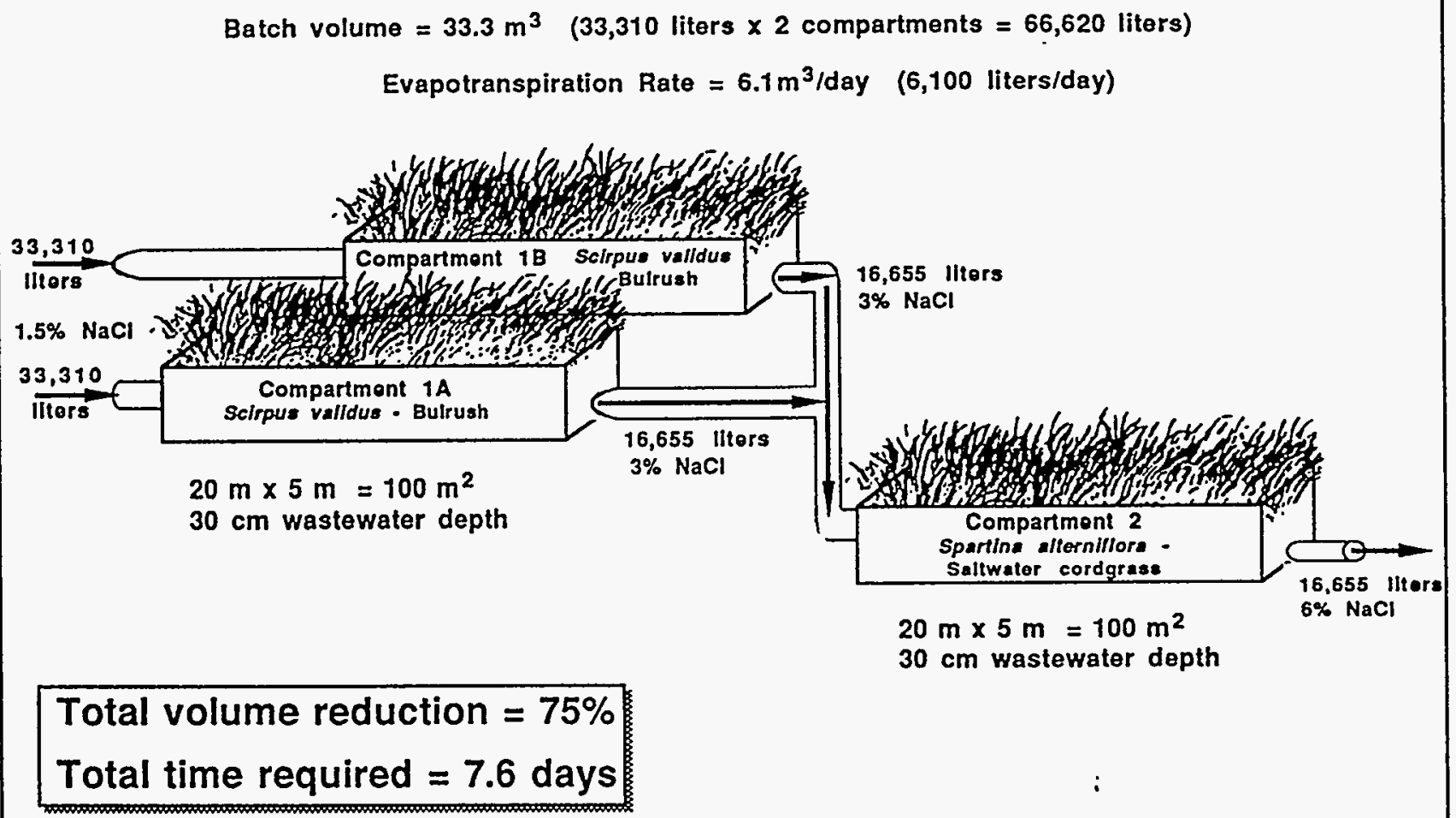


Figure 5

The pilot demonstration of the halophyte bioreactor at Devon Energy Co.

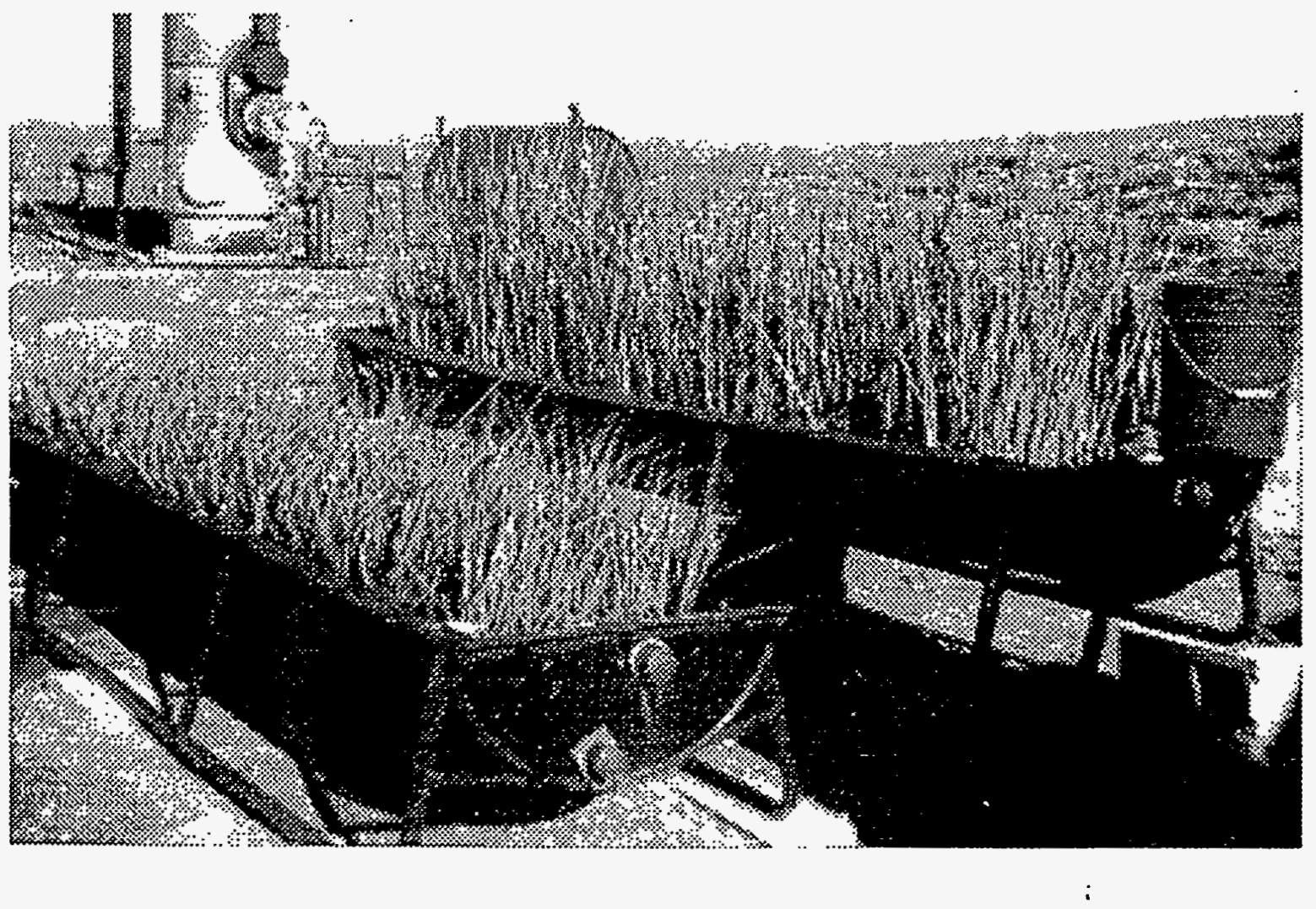

